\title{
Adult height prediction by bone age determination in children with isolated growth hormone deficiency
}

\author{
Thomas Reinehr ${ }^{1}$, Martin Carlsson ${ }^{2}$, Dionisios Chrysis ${ }^{3}$ and Cecilia Camacho-Hübner ${ }^{2}$ \\ 'Pediatric Endocrinology, Diabetes and Nutrition Medicine, Vestische Children's Hospital, University of Witten/Herdecke, Datteln, Germany \\ 2Endocrine Care, Pfizer Inc, New York, New York, USA \\ ${ }^{3}$ Division of Pediatric Endocrinology, University of Patras, Patras, Greece
}

Correspondence should be addressed to T Reinehr: T.Reinehr@kinderklinik-datteln.de

\begin{abstract}
Background: The precision of adult height prediction by bone age determination in children with idiopathic growth hormone deficiency (IGHD) is unknown.

Methods: The near adult height (NAH) of patients with IGHD in the KIGS database was compared retrospectively to adult height prediction calculated by the Bayley-Pinneau (BP) prediction based on bone age by Greulich-Pyle (GP) in 315 children and based on the Tanner-Whitehouse 2 (TW2) method in 121 children. Multiple linear regression analyses adjusted for age at GH start, age at puberty, mean dose and years of of GH treatment, and maximum GH peak in stimulation test were calculated.

Results: The mean underestimation of adult height based on the BP method was at baseline $4.1 \pm 0.7 \mathrm{~cm}$ in girls and $6.1 \pm 0.6 \mathrm{~cm}$ in boys, at 1 year of GH treatment $2.5 \pm 0.5 \mathrm{~cm}$ in girls and $0.9 \pm 0.4 \mathrm{~cm}$ in boys, while at last bone age determination adult height was overestimated in mean by $0.4 \pm 0.6 \mathrm{~cm}$ in girls and $3.8 \pm 0.5 \mathrm{~cm}$ in boys. The mean underestimation of adult height based on the TW2 method was at baseline $5.3 \pm 2.0 \mathrm{~cm}$ in girls and $7.9 \pm 0.8 \mathrm{~cm}$ in boys, at 1 year of $\mathrm{GH}$ treatment adult height was overestimated in girls $0.1 \pm 0.6 \mathrm{~cm}$ in girls and underestimated $4.1 \pm 0.4 \mathrm{~cm}$ in boys, while at last bone age determination adult height was overestimated in mean by $3.1 \pm 1.5 \mathrm{~cm}$ in girls and $3.6 \pm 0.8 \mathrm{~cm}$ in boys.

Conclusions: Height prediction by BP and TW2 at onset of GH treatment underestimates adult height in prepubertal IGHD children, while in mean 6 years after onset of GH treatment these prediction methods overestimated adult height.
\end{abstract}

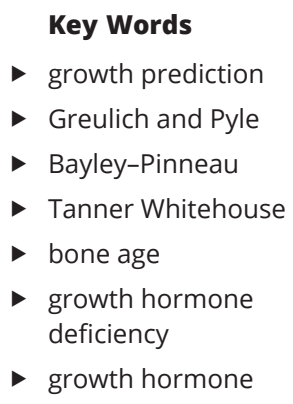

Endocrine Connections (2020) 9, 370-378

\section{Introduction}

Prediction of adult height is a frequently requested procedure in pediatric endocrinology. The commonly used methods for adult height prediction are bone age determination of the wrist and fingers of the left hand by Greulich-Pyle (GP) (1) and calculation of predicted height by the method of Bayley-Pinneau (BP) (2) or the Tanner Whitehouse 2 (TW2) method (3).

While bone age predicts with acceptable accuracy the adult height in healthy children $(4,5,6)$, in children with congenital adrenal hyperplasia (7) and growth disorders such as normal short stature $(4,8,9)$, constitutional delay of growth and puberty (CDGP) $(9,10,11)$, and idiopathic short stature (12), it has been reported that adult height is lower than predicted height. The difference between predicted and achieved adult height depends on bone age retardation in $\operatorname{CDGP}(8,9,11)$.

Since bone age is delayed in children with growth hormone deficiency (GHD) before the initiation of GH 
treatment and adult height in children with GHD is lower compared to target height even though the children were treated adequately with growth hormone (GH) (13), we hypothesize that adult height prediction based on bone age will overestimate adult height. Since data on adult height prediction based on bone age in children with (GHD) are scarce (14), we analyzed the difference between adult height prediction by bone age and near adult height in greater than 300 children with isolated growth hormone deficiency (IGHD) treated with GH, in order to give the patients with IGHD and its parents a realistic prognosis of their adult height.

\section{Materials and methods}

Patients were recruited from KIGS (Pfizer International Growth Database) from 1987 to 2012 when the KIGS database transitioned to a static database. KIGS was conducted according to a non-interventional protocol approved by the ethics committee of the participating centers, and written informed consent was obtained from all parents. All patients included in the present analysis met the following criteria: (a) diagnosis of isolated growth hormone deficiency (IGHD) (KIGS codes 1.1 as defined by the KIGS etiology classification list $(15,16,17)$ with maximum GH levels within at least two GH stimulation tests $<10 \mathrm{ng} / \mathrm{mL}$ ); (b) prepubertal stage (Tanner breast stage $<$ B2/Tanner genital stage $<2$ and testicular volume $<4 \mathrm{~mL}(18,19))$ at the onset of GH treatment; and (c) data on near adult height (NAH) (defined by a height velocity $<2 \mathrm{~cm} /$ year during the last year and an age above 14 years) were available; (d) treatment with GH for at least 4 years and more than 1 year prepubertal GH treatment; (e) bone age reported at any age $\geq 7$ years determined by GreulichPyle (1) or Tanner/Whitehouse TW2 (3). Only bone ages $>7$ years were used for analyses since a bone age $<7.5$ years has only a very low predictive value for calculation of adult height (4). We used the 20-bones method evaluating 13 long or short bones of the fingers and 7 carpals for TW2 $(3,4)$.

The retrospective data analyses were done according to principles and common practices within KIGS (16, 17): In particular, data of height and height velocity were compared with Swiss references (20). The mid-parent height SD score was calculated as the (father's height SD score+mother's height SD score)/1.61 (21). The dose of GH was expressed in terms of $\mathrm{mg} / \mathrm{kg}$ body weight per week. All patients received daily injections of GH.

\section{Statistical analysis}

Boys and girls were analyzed separately. All variables were expressed in terms of medians and 10th and 90th percentiles or means and standard error. SD scores (SDS) were calculated as patient parameter minus mean of the reference population for the patient's age divided by the S.D. of the reference population.

Univariate correlation was calculated by Pearson correlation. Bland-Altman (B\&A) plot analysis, which plots the difference between two measures against the mean of the two measures, was performed to determine the degree of agreement between the accuracy of BP and TW2 methods and to evaluate a potential bias between the mean differences, and to estimate an agreement interval, within which $95 \%$ of the differences of the TW2, compared to the BP data-points will fall. The B\&A analysis was carried out since the correlation measures only the strength of a relation between two variables, not the actual agreement (22).

Furthermore, multiple linear regression analyses with the dependent variable $\mathrm{NAH}$ minus predicted height by bone age including as independent variables age at GH start, age at puberty start, mean dose of GH treatment, years of GH treatment, maximum GH peak in GH stimulation test, and gender were calculated (model A). Furthermore, the same analyses were performed also including target height as independent variable in separate models (model B). Additionally, we calculated the mean difference between NAH and predicted adult height at baseline, after 1 year of GH treatment and at last bone age summarizing all bone ages.

Severity of GHD was defined by maximum GH peaks in GH stimulation test (severe: max GH peak $\leq 3 \mathrm{ng} / \mathrm{mL}$, moderate: $\max \mathrm{GH}$ peak $>3 \mathrm{ng} / \mathrm{mL}$ ).

Due to the low number of patients with bone age $>11$ years in boys $(n=30)$ and bone $>10$ years $(n=19)$ in girls before onset of GH treatment these measurements were excluded from analyses.

The level of significance was set at 0.05 . Wilcoxon rank-sum test was applied for comparisons. To maintain an overall significance level of 0.05 , we used the HolmBonferroni method of multiple comparisons testing for our outcomes. Since our study focused on assessing the difference between adult height prediction by bone age and near adult height, the lower type II error rate in the Bonferroni-Holm approach makes it more appropriate than the traditional Bonferroni correction (23).

$\mathrm{SAS}^{\circledast}$ version SAS, version 9.4 (SAS Institute) was used for all statistical analyses.

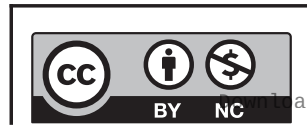

This work is licensed under a Creative Commons Attribution-NonCommercial 4.0 International License. ded from Bioscientifica.com at 04/26/2023 11:13:31AM via free access 


\section{Results}

A total of 122 females and 193 males with IGHD and adult height prediction by the GP and BP methods were included in the analyses as well as 22 girls and 99 males with adult height prediction by the TW2 methods. The patients with height prediction by BP or TW2 did not differ according to age at baseline, bone age delay at baseline, target height, doses of GH, years on $\mathrm{GH}$, age at last visit, age at puberty, or time between first and last visit with bone age determination (Table 1).

At baseline, $83 \%$ of the children had a retarded bone age $>1$ year in the BP group and $82 \%$ in the TW2 group. After 1 year of GH treatment $80 \%$ of the children had a retarded bone age $>1$ year in the BP group and $73 \%$ in the TW2 group. At last visit with bone age determination, $35 \%$ of the children had a retarded bone age $>1$ year in the BP group and 36\% in the TW2 group, while $7 \%$ of the children had an advanced bone age $>1$ year in the BP group and $12 \%$ in the TW2 group.

The difference between NAH and target height was in median -3.3 (10th/90th centile: $-10.1,-3.4) \mathrm{cm}$ in girls and in median -3.0 (10th/90th centile: $-11.8,-4.8) \mathrm{cm}$ in boys.
$\mathrm{NAH}$ was positively related to target height, height prediction by both methods of bone age determination and to a less extent with GH dose and years on GH treatment (Table 2).

\section{Comparison of adult height prediction between BP and TW2}

The adult height prediction correlated strongly between BP and TW2 at baseline $(r=0.74, P<0.001)$, at 1 year of GH treatment $(r=0.82, P<0.001)$ as well as at the last performed bone age $(r=0.87, P<0.001)$. Adult height prediction did not differ significantly $(P=0.362)$ between BP and TW2 (Fig. 1).

\section{Adult height prediction by BP}

In multiple linear regression analyses adjusted for age at GH start, age at puberty, mean dose of GH treatment, and years of $\mathrm{GH}$ treatment, the mean underestimation of adult height based on all bone ages was at baseline $4.1 \pm 0.7 \mathrm{~cm}(P<0.001)$ in girls and 6.1 $\pm 0.6(P<0.001)$ in boys, at 1 year of $\mathrm{GH}$ treatment $2.5 \pm 0.5 \mathrm{~cm}(P<0.001)$ in girls and $0.9 \pm 0.4 \mathrm{~cm}(P=0.313)$ in boys, while at last bone age determination adult height was underestimated in

Table 1 Clinical characteristics of the children with isolated growth hormone deficiency and adult height prediction based on BP or TW2 at onset and during growth hormone treatment.

Number
Baseline
Birth weight
Age (years)
Age at puberty start (years)
Height SDS
Bone age (years)
Bone age delay (years)
GH peak on stimulation test
(ng/ml)
Target height ( cm)
Height SDS- target height SDS
During GH
Dose GH ( $\mu$ g/kg/day)
Years on GH treatment
GH responsiveness (SRs)
Mean observation period
between first bone and
last bone
Age at near adult height
(years)

\begin{tabular}{|c|c|}
\hline \multicolumn{2}{|c|}{$\mathbf{B P}$} \\
\hline Female & Male \\
\hline 122 & 193 \\
\hline $3000(2360,3700)$ & $3200(2580,3800)$ \\
\hline $10.4(9.0,11.9)$ & $11.3(9.8,13.1)$ \\
\hline $12.5(11.1,14.1)$ & $13.4(11.9,15.4)$ \\
\hline$-2.8(-3.6,-1.9)$ & $-2.7(-3.5,-1.9)$ \\
\hline $8.5(7.5,10.0)$ & $9.4(8.0,10.7)$ \\
\hline $2.0(0.7,3.2)$ & $2.0(0.7,3.5)$ \\
\hline $6.8(3.0,9.6)$ & $6.3(2.3,9.0)$ \\
\hline $157.2(150.1,164.3)$ & $171.4(165.0,178.6)$ \\
\hline$-1.4(-2.8,-0.5)$ & $-1.6(-3.0,-0.7)$ \\
\hline $26.0(18.9,37.7)$ & $27.8(17.5,38.2)$ \\
\hline $5.4(4.3,7.1)$ & $6.1(4.9,8.0)$ \\
\hline $0.4(-1.0,2.7)$ & $-0.3(-1.4,0.7)$ \\
\hline $5.8(4.4,7.6)$ & $6.5(5.1,8.7)$ \\
\hline $16.2(15.0,18.7)$ & $17.9(16.6,19.8)$ \\
\hline
\end{tabular}
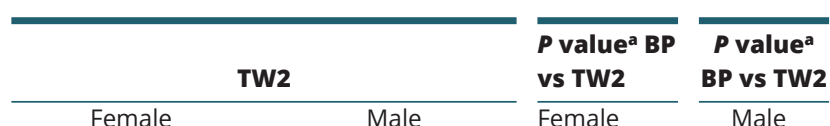

\begin{tabular}{ccc}
\hline Female & & Male \\
22 & & 99 \\
$3170(2380,3880)$ & $3252.5(2340,3920)$
\end{tabular}

Female

Male

$\begin{array}{lc}10.6(9.6,11.5) & 10.8(9.1,13.0) \\ 12.9(11.4,17.6) & 13.0(11.9,14.8) \\ -2.9(-3.8,-1.8) & -2.5(-3.6,-1.8) \\ 8.6(7.5,9.8) & 9.0(7.5,10.3) \\ 2.2(0.5,-2.9) & 2.0(0.5,3.4) \\ 6.4(1.9,8.5) & 6.1(2.8,9.3)\end{array}$

NS

NS

$158.8(151.5,167.5) \quad 172.5(166.3,179.0)$

$-2.0(-2.9,-1.1)$

$-1.7(-2.8,-1.0)$

$25.3(18.8,37.5)$

$5.8(4.4,8.6)$

$1.2(0.5,2.8)$

$6.1(5.2,8.6)$

$32.3(22.9,38.4)$

$6.8(5.0,9.0)$

$-0.3(-1.0,0.6)$

$7.6(5.4,9.6)$

$\begin{array}{lc}\text { NS } & \text { NS } \\ \text { NS } & \text { NS } \\ \text { NS } & \text { NS } \\ \text { NS } & \text { NS } \\ \text { NS } & \text { NS } \\ \text { NS } & \text { NS } \\ & \\ \text { NS } & \text { NS } \\ \text { NS } & \text { NS } \\ \text { NS } & \text { NS } \\ & \\ \text { NS } & 0.016 \\ \text { NS } & \text { NS } \\ \text { NS } & 0.002\end{array}$

Data are presented as median and 10/90th percentile.

aBonferroni-Holm's correction method was used to reduce the probability of a type I error occurring when multiple testing. NS, not significant.

https://ec.bioscientifica.com

https://doi.org/10.1530/EC-20-0090 (c) 2020 The authors Published by Bioscientifica Ltd
$16.8(15.6,18.9)$
NS

NS

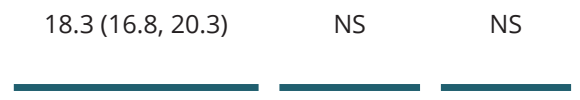


Table 2 Association between near adult height, height prediction by bone age determination, treatment parameters, and clinical characteristics (Pearson correlation) in children with isolated growth hormone deficiency.

\begin{tabular}{|c|c|c|c|c|}
\hline & \multicolumn{2}{|c|}{ GP } & \multicolumn{2}{|c|}{ TW2 } \\
\hline & $r$ & $P$ & $r$ & $P$ \\
\hline Predicted height by bone age determination & 0.82 & $<0.001$ & 0.74 & $<0.001$ \\
\hline GH dose & 0.19 & 0.001 & 0.38 & $<0.001$ \\
\hline Years on GH treatment & 0.20 & $<0.001$ & 0.26 & 0.012 \\
\hline GH responsiveness (SRs) & -0.31 & 0.014 & -0.11 & NS \\
\hline Target height & 0.79 & $<0.001$ & 0.78 & $<0.001$ \\
\hline Age at puberty start & 0.16 & NS & 0.21 & NS \\
\hline Delta bone age- chronological age & -0.06 & NS & -0.06 & NS \\
\hline Max GH peak in $\mathrm{GH}$ stimulation tests & -0.19 & $<0.001$ & -0.13 & NS \\
\hline
\end{tabular}

Bonferroni-Holm's correction method was used to reduce the probability of a type I error occurring when multiple testing.

mean by $0.4 \pm 0.6 \mathrm{~cm}(P=0.451)$ in girls and overestimated $3.8 \pm 0.5(P<0.001)$ in boys.

Including also target height in these models revealed that the mean underestimation of adult height was at baseline $5.0 \pm 1.0 \mathrm{~cm}(P<0.001)$ in girls and $5.2 \pm 0.8 \mathrm{~cm}$ $(P<0.001)$ in boys, $4.8 \pm 0.7 \mathrm{~cm}(P<0.001)$ in girls and $-0.6 \pm 0.5 \mathrm{~cm}(P=0.254)$ in boys after 1-year GH treatment, while at last bone age determination adult height was overestimated in mean by $0.2 \pm 0.7 \mathrm{~cm}(P<0.804)$ in girls and $3.2 \pm 0.6 \mathrm{~cm}(P<0.001)$ in boys.

The difference between NAH and predicted height separated to time point of bone age determination (baseline, after 1-year treatment, and last bone age) are demonstrated in Table 3 for boys and in Table 4 for girls. Height prediction by bone age determination underestimated adult height at bone ages $\geq 7.5$ years in boys and $>7.5$ years in girls at baseline, underestimated adult height at bone ages $>9.0$ years in boys and $\geq 9$ years in girls 1 year after onset of GH treatment (Fig. 2).

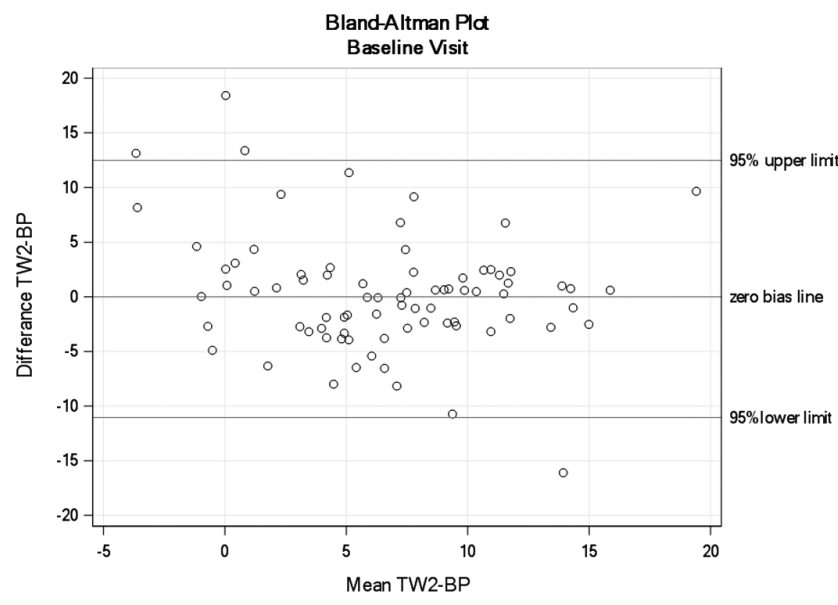

Figure 1

Comparison of mean difference between near adult height (NAH) and predicted height by GP or TW2 (Bland-Altman plot).
In contrast, the degree of overestimation at last bone age was higher in lower matured bone age compared to higher matured bone age in both gender at any bone age (Fig. 2 and Tables 3, 4).

The degree of underestimation at baseline was slightly higher in children with severe GHD compared to moderate GHD. In contrast, the degree of overestimation at last bone age was higher in children with severe GHD compared to moderate GHD.

The mean underestimation of adult height was at baseline $5.5 \pm 1.3 \mathrm{~cm}(P<0.001)$ in children with severe GHD and $5.0 \pm 0.5 \mathrm{~cm} \quad(P<0.001)$ in children with moderate GHD, at 1 year of GH treatment $5.2 \pm 1.4 \mathrm{~cm}$ $(P<0.001)$ in girls and $1.4 \pm 0.9 \mathrm{~cm}(P=0.155)$ in boys with severe GHDs vs $2.3 \pm 0.6 \mathrm{~cm}$ in girls $(P<0.001)$ and $0.9 \pm 0.4$ $(P=0.031)$ in boys with moderate GHD, while at last bone age determination adult height was overestimated in mean by $0.8 \pm 0.9 \mathrm{~cm}(P=0.358)$ in girls and $3.5 \pm 0.7$ $\mathrm{cm}(P<0.001)$ in boys with severe GHDs vs $0.6 \pm 0.7 \mathrm{~cm}$ in girls $(P=0.372)$ and $3.6 \pm 0.6(P<0.001)$ in boys with moderate GHD.

Separating the children to age at NAH $<18$ years in boys and $<17$ years in girls and NAH $\geq 18$ years in boys and $\geq 17$ years derived the same findings (data not shown).

\section{Adult height prediction by TW2}

Based on the TW2, we found similar findings with underestimation of predicted adult height based on bone ages before GH treatment and after 1-year GH treatment as well as an overestimation of predicted adult height at last bone age both in boys and girls (Supplementary Tables 1 and 2 , see section on supplementary materials given at the end of this article). The mean underestimation of adult height based on the TW2 method was at baseline $5.3 \pm 2.0 \mathrm{~cm}$ in girls and $7.9 \pm 0.8 \mathrm{~cm}$ in boys, at 1 year of $\mathrm{GH}$ treatment adult height was overestimated $0.13 \pm 0.9 \mathrm{~cm}$ 


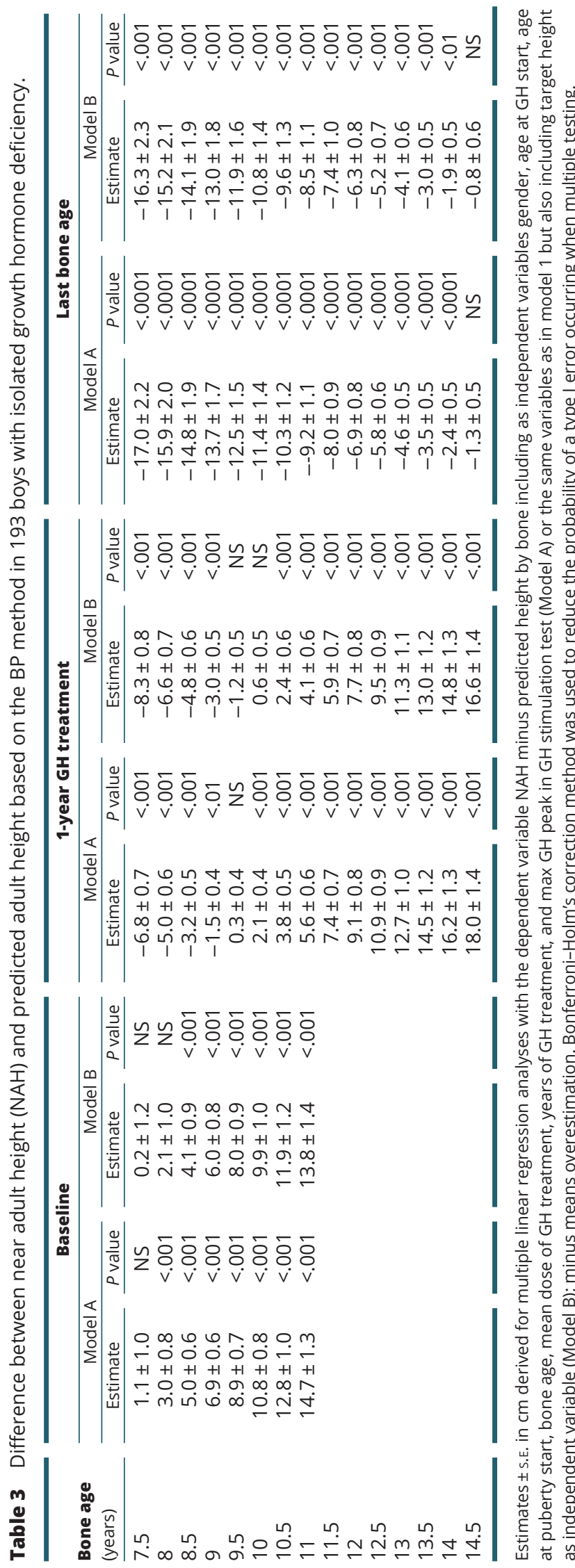

https://ec.bioscientifica.com https://doi.org/10.1530/EC-20-0090

C 2020 The authors Published by Bioscientifica Ltd
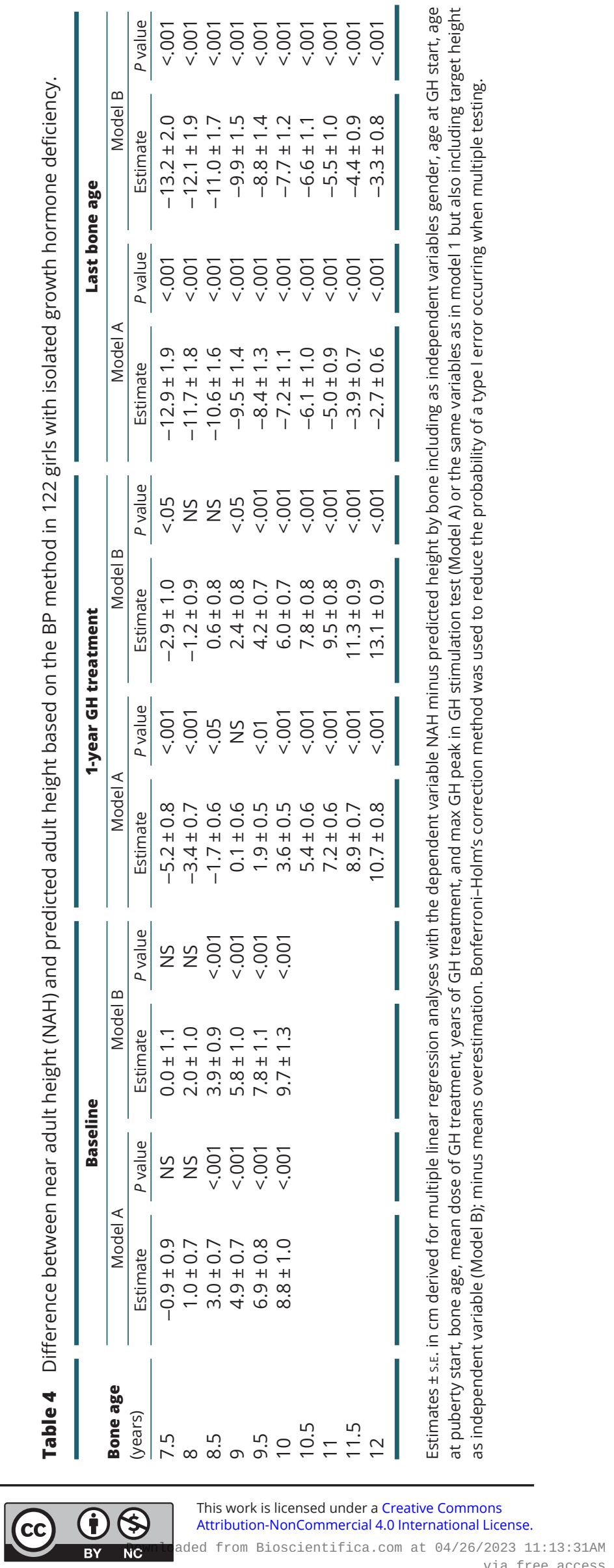
A $\mathrm{NAH}$-predicted adult height in males

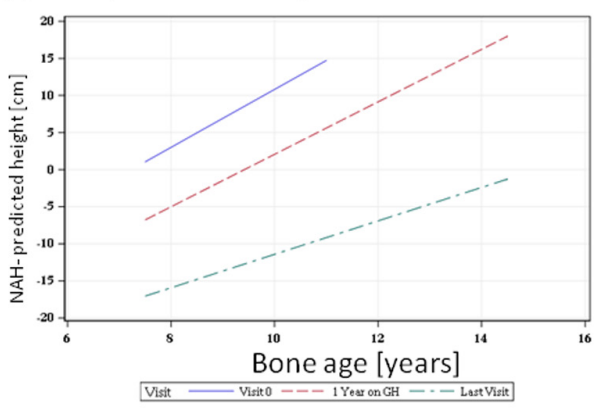

$\mathrm{B} \mathrm{NAH}$ - predicted adult height in females

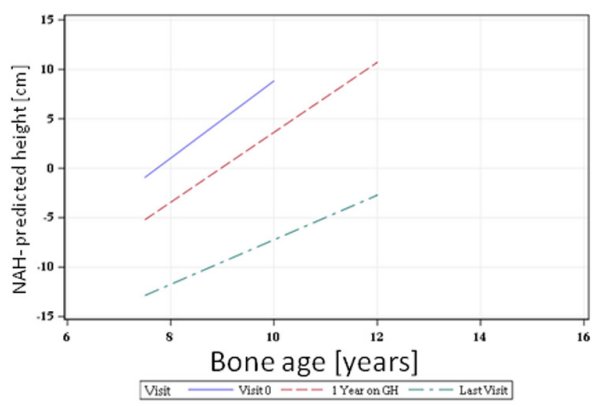

Figure 2

Difference between near adult height $(\mathrm{NAH})$ and predicted adult height based on the BP method in boys (A) and girls (B) with isolated growth hormone deficiency (calculation based on model $A$ ).

in girls and underestimated $4.1 \pm 0.4 \mathrm{~cm}$ in boys, while at last bone age determination adult height was overestimated in mean by $3.1 \pm 1.5 \mathrm{~cm}$ in girls and $3.6 \pm 0.8$ $\mathrm{cm}$ in boys.

\section{Influence factors on bone age advancement during GH treatment}

Bone age advancement based on the GP method between baseline and last bone age during GH treatment was significantly related to years of GH treatment $(r=0.26$, $P=0.038)$. We found no significant association for mean GH dose $(r=-0.09)$, age at puberty $(r=0.29)$ and age at onset of GH treatment $(r=0.16)$.

\section{Discussion}

This is to our best knowledge the first study analyzing the predictive value of adult height prediction by bone age determination in a large cohort of children with IGHD treated with GH. We found an underestimation of adult height of nearly $4 \mathrm{~cm}$ in prepubertal boys and of nearly 4 $\mathrm{cm}$ in prepubertal girls based on the BP method analyzing bone ages determined before the onset of GH treatment, and an overestimation of adult height of nearly $4 \mathrm{~cm}$ in boys and $1 \mathrm{~cm}$ in girls at last bone age derived during $\mathrm{GH}$ treatment. These findings suggest limitations of the method of height prediction on bone ages in children with IGHD in contrast to healthy children, in which adult height prediction based on bone ages corresponds well to adult height $(4,5,6)$.

One reason for the lower accuracy of height prediction in children with IGHD is likely that the commonly used methods are developed based on data of children with normal height and not short-statured children (24). Another well-known factor limiting adult height prediction is the extensive bone age retardation or acceleration. As expected, the great majority of our children with IGHD demonstrated bone age retardation at baseline, while this number decreased during $\mathrm{GH}$ treatment. In children with CDGP bone retardation $>1$ year leads to overestimation of adult height $(11,25)$. In contrast to children with CDGP, bone age determination leads to an underestimation of adult height in our study at baseline suggesting a positive impact of GH treatment on adult height. In this line, longer treatment duration of $\mathrm{GH}$ and dose of GH were positive associated with NAH. The underestimation of adult height at onset of GH treatment fits well to studies in girls with Turner syndrome receiving GH (26) or in children with GHD treated with GH (14). Importantly, children improving their height for bone age in the first years of treatment progressively increased their adult height stature (14). It is well known that GH and insulin-like growth factor (IGF-I) have also an impact on bone age $(4,26,27)$. Therefore, deficiencies in GH and IGF-I lead to growth impairment and bone age delay, while overproduction or administration of GH and IGF-I causes bone age advancement (4). Accordingly, bone age advancement was positively correlated with years of $\mathrm{GH}$ treatment and GH doses in our study.

At onset of $\mathrm{GH}$ treatment the underestimation of adult height increases with bone age obtained at an older age. This is in contrast to studies in girls with Turner syndrome treated with $\mathrm{GH}$, in which a bone age obtained at a younger age at baseline predicted a higher adult height gain through GH treatment (26). We can only speculate for the underlying reasons. Firstly, this increase of underestimation with bone age obtained at older age could be explained mathematically. At an older age the period of growth without GH treatment in IGHD children is longer than at a younger age. Therefore, the prediction of adult is lower since is based on a longer period on low height velocity due to a missing treatment of GH deficiency. Secondly, the physiology of the growth plate

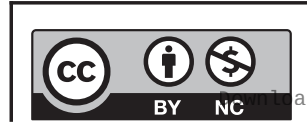

This work is licensed under a Creative Commons Attribution-NonCommercial 4.0 International License. ded from Bioscientifica.com at 04/26/2023 11:13:31AM via free access 
in IGHD is probably altered and as longer GHD stays the disturbance in bone maturation is altered more. Maybe the longstanding GHD is a permissive situation for GH or other proteins which mature the growth plate to act with a more potent way. This is supported by the fact that GH treatment decreases the underestimation. This means that there is a great ability of catch-up growth even after a long period of GHD state without treatment with GH in prepubertal children with IGHD.

As hypothesized, adult height prediction at pubertal age with a mean 6 years of GH treatment overestimates adult height in our study and this effect became smaller as bone age advanced. This fits well to the observation that adult height in children with IGHD is lower compared to target height in children even though they were treated adequately with GH $(13,15,27)$. An inability of bone age to predict the timing of the pubertal growth spurt has been reported (24) which may explain the overestimation of adult height. The pubertal growth spurt in children with IGHD may be shorter or its degree may be lower compared to healthy children $(13,27)$. Hochberg et al. reported in a retrospective study of 65 male patients with GH deficiency, that the predicted gained height over 3 years of therapy declined, in correlation with age, and became negative at pubertal age (28). They concluded that while GH induced an acceleration of growth, the advanced age of pubertal onset and accelerated pubertal progression led in turn to expedited bone maturation and thereby restricted predicted adult height gain from GH therapy (28). Furthermore, GH improves adult height in the first years of treatment and only to a much lesser extent during puberty not only in children with GHD (13, $14)$, but also in other conditions treated with GH such as Turner syndrome (29) or SHOX deficiency (30). Therefore, these hypotheses might explain why GH treated children with IGHD grow less than healthy children during puberty.

In contrast to Cacciari and colleagues (14), we found no differences between girls and boys. Cacciari et al. reported an overestimation of adult height in children with GH deficiency only in girls but not in boys. However, their study sample was much smaller $(n=83)$ than our study cohort probably explaining this difference.

The advantage of our study is the large study sample of a well-defined cohort of children with IGHD treated with GH. However, potential limitations of the study must be considered. Firstly, although manual bone age assessment methods have been used for a long time, a main problem with these methods is inter- and intra-observer variability (4). Bone age was not derived centrally but by different clinicians which might influence the finding but reflects the clinical reality. However, this limitation is a random error not influencing the primary outcome. TW2 has been reported to have a higher reproducibility than BP in most studies $(4,5,31)$, while other studies reported a higher predictive value of the BP method in short statured children $(9,32)$ or children with constitutional delay of growth (10). In our study, the findings did not differ between TW2 and BP. Furthermore, the strong correlation we found between adult height prediction based on both GP and TW2 methods suggests that both methods can be used in final height prediction considering the limitations reported in previous but also in the present study. New methods for bone age determination have been developed based on MRI, ultrasonography and computer-based analyses of X-ray of the left hand (boneExpert) (4). Future studies have to determine whether these methods have advantages in predicting adult height in IGHD children compared to the conventional used methods such as BP and TW2. Secondly, although the bone maturation process itself is similar among all people, the rate of bone maturation differs among ethnic groups (4). GP as basis of BP was developed for Caucasian and were obtained between 1931 and 1942 (1). The TW2 method was developed using radiographs of average socioeconomic class children in the United Kingdom, and the radiographs were collected in the 1950s and 1960s (3). Since the KIGS cohort of IGHD children treated with GH have been based on data of children around the world, multiple ethnicities are included (27) probably also explaining the difference of predicted height and NAH also at least in part. Thirdly, the decision to derive a bone age might differ between the different centers probably also influencing our findings. Fourthly, we cannot rule out that children with CDGP maybe misclassified as GHD in our cohort since the median age at onset of GH treatment was 11 years in boys and 10 years in girls. However, separating to children according to age when reaching near adult height and separating the children according to maximum GH peak in GH stimulation test to account for this potential confounder derived similar findings pointing against the hypothesis that CDGP may explain our findings. Furthermore, the underestimation of adult height at onset of GH treatment by bone age determination in our study in contrast to an overestimation of adult height by bone age determination in boys with proven CDPG (11) suggests a catch-up growth after starting GH treatment. This observation points against the diagnoses of CDPG in our children. Fifthly, we have no independent cohort of GH treated IGHD children. Therefore, we cannot develop 
a new prediction model for GH-treated IGHD children based on our findings, which has to be validated in an independent cohort as recently performed for adult height prediction in boys with constitutional delay of growth and puberty (11). Sixthly, this is a retrospective study and ideally the findings should be confirmed in prospective studies. Finally, we have no adult height but near adult height data. Therefore, the overestimation at last bone age may be lower than calculated in this study. However, the underestimation of adult height prediction by bone at onset of GH treatment would be greater if further growth between NAH and adult height would occur.

In summary, our study demonstrated that adult height prediction by bone age determination at onset and during the first year of GH treatment in prepubertal IGHD children underestimates adult height. In contrast, adult height prediction based on bone ages performed in mean 6 years after onset of GH treatment overestimated adult height. These findings were shown for both the BP and TW2 method. This has to be kept in mind when predicting adult height based on bone age in children with IGHD.

\section{Supplementary materials}

This is linked to the online version of the paper at https://doi.org/10.1530/ EC-20-0090

\section{Declaration of interest}

Martin Carlsson and Cecilia Camacho-Hübner who are full-time employees of Pfizer Endocrine Care. Thomas Reinehr and Dionisios Chrysis were members of the KIGS Steering Committee at the time of this study.

\section{Funding}

This study was sponsored by Pfizer.

\section{Acknowledgement}

The authors would like to thank all physicians who contributed data from their patients to the KIGS (Pfizer International Growth Database) database.

\section{References}

1 Greulich WW \& Pyle S. Radiograph Atlas of Skeletal Development of the Hand and Wrist, 2nd ed. Redwood City, CA, USA: Stanford University Press, 1959.

2 Bayley N \& Pinneau SR. Tables for predicting adult height from skeletal age: revised for use with the Greulich-Pyle hand standards. Journal of Pediatrics 195240 423-441. (https://doi.org/10.1016/s00223476(52)80205-7)

3 Tanner J, Whitehouse R, Cameron N, Marshall W, Healy M \& Goldstein H. Assessment of Skeletal Maturity and Prediction of Adult Height (TW2 Method). London, UK: Academic Press, 1983.

4 Satoh M. Bone age: assessment methods and clinical applications. Clinical Pediatric Endocrinology 201524 143-152. (https://doi. org/10.1297/cpe.24.143)
5 Roemmich JN, Blizzard RM, Peddada SD, Malina RM, Roche AF, Tanner JM \& Rogol AD. Longitudinal assessment of hormonal and physical alterations during normal puberty in boys. IV: Predictions of adult height by the Bayley-Pinneau, Roche-Wainer-Thissen, and Tanner-Whitehouse methods compared. American Journal of Human Biology 19979 371-380. (https://doi.org/10.1002/(SICI)15206300(1997)9:3<371::AID-AJHB9>3.0.CO;2-0)

6 Ostojic SM. Prediction of adult height by Tanner-Whitehouse method in young Caucasian male athletes. QJM 2013106 341-345. (https://doi.org/10.1093/qjmed/hcs230)

7 Bonfig W \& Schwarz HP. Overestimation of final height prediction in patients with classical congenital adrenal hyperplasia using the Bayley and Pinneau method. Journal of Pediatric Endocrinology and Metabolism 201225 645-649. (https://doi.org/10.1515/jpem-2012-0122)

8 Maes M, Vandeweghe M, Du Caju M, Ernould C, Bourguignon JP \& Massa G. A valuable improvement of adult height prediction methods in short normal children. Hormone Research 199748 184-190. (https://doi.org/10.1159/000185511)

9 Bramswig JH, Fasse M, Holthoff ML, von Lengerke HJ, von PW \& Schellong G. Adult height in boys and girls with untreated short stature and constitutional delay of growth and puberty: accuracy of five different methods of height prediction. Journal of Pediatrics 1990 117 886-891. (https://doi.org/10.1016/s0022-3476(05)80127-1)

10 Sperlich M, Butenandt O \& Schwarz HP. Final height and predicted height in boys with untreated constitutional growth delay. European Journal of Pediatrics 1995154 627-632. (https://doi.org/10.1007/ bf02079065)

11 Reinehr T, Hoffmann E, Rothermel J, Lehrian TJ, Bramswig J \& Binder G. A new model of adult height prediction validated in boys with constitutional delay of growth and puberty. Hormone Research in Paediatrics 201991 186-194. (https://doi.org/10.1159/000499712)

12 Topor LS, Feldman HA, Bauchner H \& Cohen LE. Variation in methods of predicting adult height for children with idiopathic short stature. Pediatrics 2010126 938-944. (https://doi.org/10.1542/ peds.2009-3649)

13 Ranke MB, Lindberg A, Mullis PE, Geffner ME, Tanaka T, Cutfield WS, Tauber M \& Dunger D. Towards optimal treatment with growth hormone in short children and adolescents: evidence and theses. Hormone Research in Paediatrics 201379 51-67. (https://doi. org/10.1159/000347121)

14 Cacciari E, Cicognani A, Pirazzoli P, Zucchini S, Salardi S, Balsamo A Cassio A, Pasini A, Carla G, Tassinari D, et al. Final height of patients treated for isolated GH deficiency: examination of 83 patients. European Journal of Endocrinology 1997137 53-60. (https://doi. org/10.1530/eje.0.1370053)

15 Ranke MB, Lindberg A \& KIGS International Board. Observed and predicted growth responses in prepubertal children with growth disorders: guidance of growth hormone treatment by empirical variables. Journal of Clinical Endocrinology and Metabolism 201095 1229-1237. (https://doi.org/10.1210/jc.2009-1471)

16 Ranke MB \& Lindberg A. Approach to predicting the growth response during growth hormone treatment. Acta Paediatrica 1996417 64-65. (https://doi.org/10.1111/j.1651-2227.1996.tb14300.x)

17 Ranke MB \& Lindberg A. Predicting growth in response to growth hormone treatment. Growth Hormone and IGF Research 200919 1-11. (https://doi.org/10.1016/j.ghir.2008.08.001)

18 Marshall WA \& Tanner JM. Variations in pattern of pubertal changes in girls. Archives of Disease in Childhood 196944 291-303. (https:// doi.org/10.1136/adc.44.235.291)

19 Marshall WA \& Tanner JM. Variations in the pattern of pubertal changes in boys. Archives of Disease in Childhood 197045 13-23. (https://doi.org/10.1136/adc.45.239.13)

20 Prader A, Largo RH, Molinari L \& Issler C. Physical growth of Swiss children from birth to 20 years of age. First Zurich longitudinal study of growth and development. Helvetica Paediatrica Acta: Supplementum 198952 1-125.

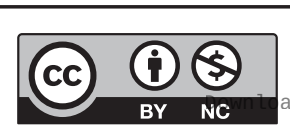

This work is licensed under a Creative Commons Attribution-NonCommercial 4.0 International License. ded from Bioscientifica.com at 04/26/2023 11:13:31AM 
21 Ranke MB. Towards a consensus on the definition of idiopathic short stature. Hormone Research 199645 (Supplement 2) 64-66. (https:// doi.org/10.1159/000184851)

22 Bland JM \& Altman DG. Statistical methods for assessing agreement between two methods of clinical measurement. Lancet $1986 \mathbf{1}$ 307-310. (https://doi.org/10.1016/j.ijnurstu.2009.10.001)

23 Holm S. A simple sequentially rejective multiple test procedure. Scandinavian Journal of Statistics 19796 65-70.

24 Preece MA. Prediction of adult height: methods and problems. Acta Paediatrica Scandinavica: Supplement 1988347 4-11.

25 Tarim O. Height predictions by Bayley-Pinneau method may misguide pediatric endocrinologists. Turkish Journal of Pediatrics 201355 485-492.

26 Sas TC, de Muinck Keizer-Schrama SM, Stijnen T, van Teunenbroek A, Hokken-Koelega AC, Waelkens JJ, Massa GG, Vulsma T, Gerver WJ, Reeser HM, et al. Final height in girls with Turner's syndrome treated with once or twice daily growth hormone injections. Dutch Advisory Group on Growth Hormone. Archives of Disease in Childhood 199980 36-41. (https://doi.org/10.1136/adc.80.1.36)

27 Ranke M, Price D \& Reiter E. Growth Hormone Therapy in Pediatrics 20 Years of KIGS, 1st ed. Basel, Switzerland: Karger AG, 2007.

28 Hochberg Z, Leiberman E, Landau H, Koren R \& Zadik Z. Age as a determinant of the impact of growth hormone therapy on predicted adult height. Clinical Endocrinology 199441 331-335. (https://doi. org/10.1111/j.1365-2265.1994.tb02553.x)

29 Sas TC, Gerver WJ, De Bruin R, Mulder PG, Cole TJ, De Waal W \& Hokken-Koelega AC. Body proportions during 6 years of GH treatment in children with short stature born small for gestational age participating in a randomised, double-blind, dose-response trial. Clinical Endocrinology 200053 675-681. (

30 Blum WF, Ross JL, Zimmermann AG, Quigley CA, Child CJ, Kalifa G, Deal C, Drop SL, Rappold G \& Cutler Jr GB. GH treatment to final height produces similar height gains in patients with SHOX deficiency and Turner syndrome: results of a multicenter trial. Journal of Clinical Endocrinology and Metabolism 201398 E1383-E1392. (https://doi.org/10.1210/jc.2013-1222)

31 Bull RK, Edwards PD, Kemp PM, Fry S \& Hughes IA. Bone age assessment: a large scale comparison of the Greulich and Pyle, and Tanner and Whitehouse (TW2) methods. Archives of Disease in Childhood 199981 172-173. (https://doi.org/10.1136/adc.81.2.172)

32 Jeong SW, Cho JH, Jung HW \& Shim KS. Near final height in Korean children referred for evaluation of short stature: clinical utility and analytical validity of height prediction methods. Annals of Pediatric Endocrinology and Metabolism 201823 28-32. (https://doi. org/10.6065/apem.2018.23.1.28)

Received in final form 12 March 2020

Accepted 7 April 2020

Accepted Manuscript published online 8 April 2020
This work is licensed under a Creative Commons Attribution-NonCommercial 4.0 International License. ded from Bioscientifica.com at 04/26/2023 11:13:31AM 